\title{
Prediction of Risk Factors after Spine Surgery in Patients Aged $>75$ Years Using the Modified Frailty Index
}

\author{
Ji-Yoon Kim, In Sung Park, ${ }^{2}$ Dong-Ho Kang, ${ }^{2}$ Young-Seok Lee, ${ }^{3}$ Kyoung-Tae Kim, ${ }^{4}$ Sung Jin Hong ${ }^{5}$ \\ Department of Anesthesiology, Pain and Critical Care Medicine,' Kyungpook National University Chilgok Hospital, School of Medicine, Kyung- \\ pook National University, Daegu, Korea \\ Department of Neurosurgery, ${ }^{2}$ Gyeongsang National University Hospital, Gyeongsang National University School of Medicine, Jinju, Korea \\ Department of Neurosurgery, ${ }^{3}$ Kyungpook National University Chilgok Hospital, School of Medicine, Kyungpook National University, Daegu, \\ Korea \\ Department of Neurosurgery, ${ }^{4}$ Kyungpook National University Hospital, School of Medicine, Kyungpook National University, Daegu, Korea \\ Department of Anesthesiology, Pain and Critical Care Medicine, Yeouido St. Mary's Hospital, College of Medicine, Catholic University of Korea, \\ Seoul, Korea
}

Objective : Spine surgery is associated with higher morbidity and mortality rates in elderly patients. The modified Frailty Index $(\mathrm{mFl})$ is an evaluation tool to determine the frailty of an individual and how preoperative status may impact postoperative survival and outcomes. This study aimed to determine the usefulness of $\mathrm{mFl}$ in predicting postoperative complications in patients aged $\geq 75$ years undergoing surgery with instrumentation.

Methods : We retrospectively reviewed the perioperative course of 137 patients who underwent thoracolumbar-instrumentation spine surgery between 2011 and 2016. The preoperative risk factors were the 11 variables of the $\mathrm{mFl}$, as well as body mass index $\left(\mathrm{kg} / \mathrm{cm}^{2}\right)$, preoperative hemoglobin, platelet, albumin, creatinine, anesthesia time, operation time, estimated blood loss, and transfusion amount. The 60-day occurrences of complication rates were used for outcome assessment.

Results : Major complications after spinal instrumentation surgery occurred in 34 of 138 patients (24.6\%). The mean mFl score was $0.18 \pm 0.12$. When we divided patients into a pre-frail group $(\mathrm{mFI}, 0.09-0.18 ; \mathrm{n}=94)$ and a frail group $(\mathrm{mFI} \geq 0.27 ; \mathrm{n}=44)$, only the rate of sepsis was statistically higher in the frail group than in the pre-frail group. There were significantly more major complications in patients with low albumin levels or in patients with infection or who had experienced trauma. The $\mathrm{mFI}$ was a more useful predictor of postoperative complications than the American Society of Anesthesiologists physical status score.

Conclusion : The $\mathrm{mFI}$ can successfully predict postoperative morbidity and mortality in patients aged $\geq 75$ years undergoing spine surgery. The $\mathrm{mFl}$ improves perioperative risk stratification that provides important information to assist in the preoperative counselling of patients and their families.

Key Words : Frail elderly · Risk assessment · Postoperative complications · Morbidity · Spine.

- Received : January 22, 2020 •Revised : February 19, 2020 •Accepted : March 11, 2020

- Address for reprints : Sung Jin Hong

Department of Anesthesiology, Pain and Critical Care Medicine, Yeouido St. Mary's Hospital, College of Medicine, Catholic University of Korea, 10 63-ro, Yeongdeungpo-gu, Seoul 07345, Korea

Tel : +82-2-3779-1097, Fax : +82-2-783-0368, E-mail : hongs@catholic.ac.kr, ORCID : https://orcid.org/0000-0001-9353-2644

This is an Open Access article distributed under the terms of the Creative Commons Attribution Non-Commercial License (http://creativecommons.org/licenses/by-nc/4.0) which permits unrestricted non-commercial use, distribution, and reproduction in any medium, provided the original work is properly cited. 


\section{INTRODUCTION}

Being elderly is generally associated with a state of decline in function during the later part of life. Although there are several definitions of elderly, it is generally accepted as a chronological age of 60 or 65 years or more in most developed countries, which is approximately equivalent to retirement age ${ }^{6)}$. However, the life expectancy of humans is lengthening almost linearly in most developed countries, without sign of deceleration. The elderly population is growing rapidly and chronological time is becoming less important in the meaning of elderly. People experience very different functional conditions when they grow older within the years defined as elderly. In developed countries, many people in their 60s and early $70 \mathrm{~s}$ remain active and live independently without help from others. Around the age of 80 years, people tend to become increasingly frail, a condition marked by serious mental and physical debilitation $^{20)}$. Therefore, many gerontologists have recognized this diversity of old age by defining several subgroups : young-old (65-74 years), middle-old (75-84 years), and oldest-old ( $\geq 85$ years) ${ }^{22)}$.

Not only due to increased life expectancy and the aging population, but also advancements in surgical and anesthetic techniques, frail elderly patients over 75 years are also very likely to undergo spinal surgery. Defining frailty is a challenge; however, it can be defined as a decreased physiological reserve of multiple organ systems ${ }^{8,9)}$. Consequently, the incidence of perioperative complications is higher in elderly patients than in younger patients, resulting in higher morbidity and mortality $^{11)}$. Thus, prediction and prevention of postoperative complications and outcomes in elderly patients are very important for patients and clinicians ${ }^{13)}$.

Frailty has been measured using different methods in the literature. The Canadian Study of Health and Aging developed a frailty index (CSHA-FI) based on history and physical examination. The CSHA-FI consists of a 70-item scale which measures the cumulative deficits associated with physical, cognitive, functional, and social domains. It is scored according to the ratio of the number of present items to the total number of items assessed ${ }^{17)}$. A modified Frailty Index (mFI), created on the basis of the CSHA-FI, comprises 11 items. It is not only simpler, but it has also been proven effective in various surgical populations ${ }^{5,12,21)}$.

To the best of our knowledge, no reports in the literature have specifically investigated the association between the frailty scale and complications in people over 75 years of age; that is, the middle-old and oldest-old. In addition, studies on spine surgery mainly focus on highly invasive surgeries, such as adult spinal deformity surgeries. In patients over 75 years of age with various systemic diseases, frailty will have a significant effect on outcomes and complications. Therefore, we conducted a study to assess the usefulness of the mFI for predicting postoperative outcomes by limiting the study subjects to more elderly patients. In fact, because the invasiveness of surgery obviously affects the postoperative course, we also studied patients who underwent a less-invasive procedure than deformity surgery. In addition to frailty, we also investigated other risk factors for complications.

\section{MATERIALS AND METHODS}

\section{Patient factors}

We obtained informed consent from all the patients and approval from the Institutional Review Board of Gyeongsang National University Hospital (approval No. 2020-01-022). We retrospectively reviewed the database records of 138 patients aged 75 years or older who underwent thoracolumbar and lumbar instrumentation (T9-S1) from 2011 to 2016.

Demographic data (age, sex, body mass index [BMI]) and the American Society of Anesthesiologists (ASA) physical-status score were collected, as well as information about surgical factors (elective or emergency, diagnosis, surgical time, anesthetic time, and estimated blood loss [EBL]). Preoperative laboratory data, including those of hemoglobin, platelet, albumin, and creatinine levels, were also investigated.

\section{$\mathrm{mFI}$}

The frailty was scored according to each patient's data. The mFI was previously described by Saxton and Velanovich and it provides a patient score based on 11 variables present in the CSHA-FI (Table 1) ${ }^{16)}$. The mFI consists of changes in everyday activity, history of diabetes mellitus, chronic obstructive pulmonary diseases, congestive heart failure, myocardial infarction, percutaneous coronary intervention, cardiac surgery, or angina, arterial hypertension, clouding or delirium, cerebrovascular accident with deficit, history of stroke, and decreased peripheral pulse. The preoperative risk factors examined were 
Table 1. Variables of the modified Frailty Index

\begin{tabular}{l}
\hline Non-independent functional status \\
History of diabetes mellitus \\
History of chronic obstructive pulmonary disease \\
History of congestive heart failure \\
History of myocardial infarction \\
History of percutaneous coronary intervention, cardiac surgery, or \\
angina \\
Hypertension requiring the use of medication \\
Peripheral vascular disease or rest pain \\
History of impaired sensorium \\
History of transient ischemic attack or cerebrovascular accident \\
History of cerebrovascular accident with deficit
\end{tabular}

the 11 variables of the $\mathrm{mFI}$, as well as body mass index $\left(\mathrm{kg} / \mathrm{cm}^{2}\right)$, preoperative hemoglobin, platelet, albumin, creatinine, anesthetic time, operation time, EBL, and transfusion amount.

\section{Outcome}

Postoperative complications were described as death, cardiac arrest, deep vein thrombosis, myocardial infarction, postoperative intubation, pulmonary embolism, stroke, sepsis, acute kidney injury, pneumonia, surgical infection, and urinary tract infection within 6 months. The mFI was calculated based on the modified frailty score. This was expressed as the ratio of the number of problems the patient has among the 11 items, thus providing an index within the range of 0 to 1 . We categorized patients as not frail $(\mathrm{mFI}=0)$, pre-frail $(0<\mathrm{mFI}<0.27)$, and frail $(\mathrm{mFI} \geq 0.27)$ based on previous data defining frailty as an index greater than $0.27^{19)}$. The duration of hospital stay was also investigated.

\section{Statistical analysis}

All data and statistical analysis were conducted using SPSS statistical software (version 21; IBM Corp., Armonk, NY, USA). Univariate analysis was performed with a t test to identify risk factors for complications. Multivariate analysis was performed to control for patient and operative variables and to assess which data are described as mean (standard deviation $[\mathrm{SD}]$ ) or median (interquartile range).
Table 2. Patient characteristics

\begin{tabular}{|c|c|}
\hline Variable & Value $(n=138)$ \\
\hline Age (years) & $78.26 \pm 2.84$ \\
\hline Sex, male/female & $82 / 56$ \\
\hline Body mass index $\left(\mathrm{kg} / \mathrm{m}^{2}\right)$ & $23.16 \pm 3.42$ \\
\hline Emergency operation & 10 \\
\hline \multicolumn{2}{|l|}{ Diagnosis } \\
\hline Degenerative disease & 79 \\
\hline Infection & 26 \\
\hline Metastasis & 5 \\
\hline Trauma & 28 \\
\hline \multicolumn{2}{|l|}{ Preoperative laboratory } \\
\hline Hemoglobin (g/dL) & $11.64 \pm 1.73$ \\
\hline Platelet $\left(\times 10^{3} / \mathrm{mm}^{3}\right)$ & $267.00 \pm 88.89$ \\
\hline Albumin (g/dL) & $3.69 \pm 0.59$ \\
\hline Creatinine (mg/dL) & $0.82 \pm 0.73$ \\
\hline \multicolumn{2}{|l|}{ Perioperative state } \\
\hline Anesthesia time (minutes) & $336.75 \pm 268.39$ \\
\hline Operative time (minutes) & $236.01 \pm 83.12$ \\
\hline Transfusion, RBC & $1104.71 \pm 1194.01$ \\
\hline Estimated blood loss (mL) & $1065.47 \pm 623.94$ \\
\hline ASA classification & $2.38 \pm 0.49$ \\
\hline Modified Frailty Index & $0.18 \pm 0.12$ \\
\hline
\end{tabular}

Values are presented as mean \pm standard deviation or number. RBC : red blood cell, ASA : American Society of Anesthesiologists

\section{RESULTS}

\section{Patient demographics}

In this study, 138 patients over the age of 76 years underwent surgical treatment using instrumentation in 2011-2016. The average age was $78.26 \pm 2.84$ years (mean \pm SD). Of the 138 patients, there were 82 men and 56 women. Their average BMI was $23.16 \pm 3.42 \mathrm{~kg} / \mathrm{m}^{2}$. Surgical diagnoses were degenerative disease (79 patients), trauma (28 patients), infection (26 patients), and metastasis (five patients). The anesthesia time was $336.75 \pm 268.39$ minutes, and the operation time was $236.01 \pm 83.12$ minutes. The intraoperative transfusion was $1104.71 \pm 1194.01 \mathrm{~mL}$, and the EBL was $1065.47 \pm 623.94 \mathrm{~mL}$. Regarding the ASA physical-status score, 85 patients (64.3\%) were II and 53 patients (35.7\%) were III. There were 17, 33, 44, and 44 patients with an mFI of $0,0.09,0.18$, and $>0.27$, respectively (Table 2). 
Table 3. Outcome and complications based on $\mathrm{mFI}$ (not frail $[\mathrm{mFl}=0]$, pre-frail $[0<\mathrm{mFl}<0.27]$, and frail $[\mathrm{mFl} \geq 0.27]$ state)

\begin{tabular}{|c|c|c|c|c|c|}
\hline & \multicolumn{4}{|c|}{$\mathrm{mFI}$} & \multirow{2}{*}{$p$-value } \\
\hline & $0(n=17)$ & $0.09(n=33)$ & $0.18(n=44)$ & $\geq 0.27(n=44)$ & \\
\hline Cardiac arrest & $1(6.0)$ & $0(0.0)$ & $0(0.0)$ & $2(5.0)$ & 0.264 \\
\hline Death & $1(6.0)$ & $2(6.0)$ & $3(7.0)$ & $4(9.0)$ & 0.950 \\
\hline Deep vein thrombosis & $1(6.0)$ & $0(0.0)$ & $1(2.0)$ & $5(11.0)$ & 0.106 \\
\hline Myocardial infarction & $0(0.0)$ & $0(0.0)$ & $3(7.0)$ & $3(7.0)$ & 0.313 \\
\hline Postoperative intubation & $0(0.0)$ & $0(0.0)$ & $0(0.0)$ & $2(5.0)$ & 0.227 \\
\hline Pulmonary embolism & $0(0.0)$ & $0(0.0)$ & $2(5.0)$ & $4(9.0)$ & 0.199 \\
\hline Sepsis* & $0(0.0)$ & $1(3.0)$ & $1(2.0)$ & $6(14.0)$ & 0.023 \\
\hline Stroke & $0(0.0)$ & $0(0.0)$ & $3(7.0)$ & $2(5.0)$ & 0.351 \\
\hline Acute kidney injury & $1(6.0)$ & $3(9.0)$ & $2(5.0)$ & $3(7.0)$ & 0.883 \\
\hline Pneumonia & $0(0.0)$ & $2(6.0)$ & $5(12.0)$ & $1(2.0)$ & 0.208 \\
\hline Superficial surgical infection & $2(12.0)$ & $6(18.0)$ & $3(7.0)$ & $3(7.0)$ & 0.327 \\
\hline Urinary tract infection & $2(12.0)$ & $2(6.0)$ & $3(7.0)$ & $7(16.0)$ & 0.425 \\
\hline Total & 8 & 16 & 26 & 42 & \\
\hline
\end{tabular}

Values are presented as number (\%). ${ }^{*} p<0.05 . \mathrm{mFl}$ : modified Frailty Index

\section{Outcome and complications according to $\mathrm{mFI}$}

At least one complication occurred in $24.6 \%$ of patients $(n=34)$ (Table 3$)$. The complications were analyzed by subgrouping patients with an mFI of $0.09-0.18$ into a pre-frail state and those with more than 0.27 into a frail state. Statistically significant, sepsis incidence was higher at higher mFI ( $p=0.023$ ). Although not statistically significant, a higher mFI trend was seen in patients with cardiac arrest, deep vein thrombosis, postoperative intubation, pulmonary embolism, and stroke.

\section{Comparison of patients with and without com- plications}

We used comparative analysis according to the presence of complications. Age, sex, and BMI did not differ between groups (Table 4). In terms of the diagnoses, complications occurred more frequently in patients with degenerative diseases and infections than in patients who had experienced trauma ( $p=0.009$ ). In terms of preoperative laboratory findings, complications occurred significantly more often when albumin levels were low $(p=0.001)$. There was no difference in anesthesia, surgery time, transfusion, or EBL between the two groups. The ASA physical-status scores did not differ between the two groups, but the $\mathrm{mFI}$ was significantly different between the two groups $(p=0.047)$. Moreover, the hospital stay was longer in the complication group than in the non-complication group $(p=0.036)$.

\section{DISCUSSION}

Frailty is defined as a state of increased vulnerability to poor resolution of homoeostasis after a stressor event, which increases the risk of adverse outcomes. Frailty represents a state of weakened reserve against even minor stressors and may not correlate to chronological age ${ }^{10)}$. Frailty is recognized as a clinical syndrome that includes unintentional weight loss (10 lbs in past year), self-reported exhaustion, weakness (grip strength), slow walking speed, and low physical activity ${ }^{6}$. The prevalence of frailty increases with age, which is associated with disability, admissions to hospital, and death ${ }^{6}$. In particular, frailty is known to be an independent factor for predicting postoperative complications in various surgical areas ${ }^{1,8,15)}$. The influence of frailty is also recognized in the area of spinal surgery ${ }^{5}$.

Flexman et al. ${ }^{5}$ investigated frailty in patients undergoing degenerative spine surgery from 2006 to 2012 . They noted that frailty was an independent predictor of major complications, in particular reoperation and postsurgical infection. In addition, frailty is an independent predictor of length of hospital 
Table 4. Comparison of patients with and without complications

\begin{tabular}{|c|c|c|c|}
\hline & Non-complication $(n=94)$ & Complication $(n=44)$ & $p$-value \\
\hline Age (years) & $78.51 \pm 2.98$ & $77.73 \pm 2.46$ & 0.107 \\
\hline Sex, male/female & $37 / 57$ & $19 / 25$ & 0.712 \\
\hline Body mass index $\left(\mathrm{kg} / \mathrm{m}^{2}\right)$ & $22.76 \pm 2.88$ & $24.10 \pm 4.26$ & 0.063 \\
\hline Emergency operation & 5 & 5 & 0.289 \\
\hline Diagnosis* & & & 0.009 \\
\hline Degenerative disease & 57 & 22 & \\
\hline Infection & 11 & 15 & \\
\hline Metastasis & 5 & 0 & \\
\hline Trauma & 21 & 7 & \\
\hline \multicolumn{4}{|l|}{ Preoperative laboratory } \\
\hline Hemoglobin (g/dL) & $11.78 \pm 1.81$ & $11.35 \pm 1.51$ & 0.183 \\
\hline Platelet $\left(\times 10^{3} / \mathrm{mm}^{3}\right)$ & $261.77 \pm 91.42$ & $278.18 \pm 83.13$ & 0.314 \\
\hline Albumin $(\mathrm{g} / \mathrm{dL})^{*}$ & $3.80 \pm 0.56$ & $3.45 \pm 0.58$ & 0.001 \\
\hline Creatinine (mg/dL) & $0.74 \pm 0.25$ & $0.97 \pm 1.24$ & 0.230 \\
\hline \multicolumn{4}{|l|}{ Perioperative state } \\
\hline Anesthesia time (minutes) & $353.48 \pm 320.63$ & $301.02 \pm 72.29$ & 0.135 \\
\hline Operative time (minutes) & $241.91 \pm 85.29$ & $223.85 \pm 77.74$ & 0.210 \\
\hline RBC transfusion $(\mathrm{mL})$ & $1159.68 \pm 1371.78$ & $987.27 \pm 671.98$ & 0.431 \\
\hline Estimated blood loss (mL) & $1071.18 \pm 1053.41$ & $1053.41 \pm 610.41$ & 0.877 \\
\hline ASA classification, 1/2/3/4/5 & 0/60/34/0/0 & 0/25/19/0/0 & 0.457 \\
\hline Modified Frailty Index* & & & 0.047 \\
\hline 0 & 14 & 3 & \\
\hline 0.09 & 27 & 6 & \\
\hline 0.18 & 30 & 14 & \\
\hline$>0.27$ & 23 & 21 & \\
\hline Hospital stay (days)* & $29.76 \pm 20.52$ & $58.98 \pm 88.73$ & 0.036 \\
\hline
\end{tabular}

Values are presented as mean \pm standard deviation or number. ${ }^{*} p<0.05$. RBC : red blood cell, ASA : American Society of Anesthesiologists

stay and discharge. In this study, using the $\mathrm{mFI} ; 87.7 \%$ of patients over 75 years were pre-frail or frail. Furthermore, the mFI was higher than the conventional ASA physical-state score. Therefore, the $\mathrm{mFI}$ is a simple tool that can predict postoperative complications; and it can be easily calculated from patient history and physical examination.

Previous studies have used the ASA physical-status classification to predict postoperative complications ${ }^{9}$. Therefore, the use of that classification as an index of risk stratification for spine surgery to understand the patient's frailty is useful as an independent predictor of postoperative complications. Ali et al. ${ }^{3)}$ studied the 30-day morbidity and mortality after spine surgery using the National surgical quality improvement pro- gram. In this study, we used the ASA physical-status classification and $\mathrm{mFI}$. The mortality rate was $1.7 \%$ in patients with $0 \mathrm{mFI}$, but $2.3 \%$ for patients with $\mathrm{mFI}>0.27(p<0.001)$. The $\mathrm{mFI}$ and rate of complications showed a dose-response relationship. In the multivariate analysis, a preoperative $\mathrm{mFI}$ and ASA physical-status classification >III was significantly associated with increased rates of postoperative complications and death. In our study, mFI was a more useful predictor of postoperative complications than the ASA physical-status score.

The $\mathrm{mFI}$ is also known for its usefulness in various surgical fields. An mFI $>0.45$ was an independent predictor of mortality and life-threatening postoperative complications following head and neck surgery ${ }^{1)}$. In addition, frailty, disability, and risk 
scores influenced the mortality rate in patients who underwent coronary artery bypass and/or valve surgery ${ }^{2}$.

Recently, Leven et al. ${ }^{13)}$ reported that the frailty index in adult spine deformity was an independent predictor of mortality and such complications as pulmonary/deep vein thrombosis, blood transfusion, pulmonary complication, and reoperation. In addition, an $\mathrm{mFI}=0.27$ was the cut-off for increased complications, mortality, and reoperation rates. In comparison with age $>60$ years and obesity class III, mFI was a superior predictor of several postoperative complications and reoperation. The above results were similar to those of our study whereby postoperative complications were higher when the mFI was $\geq 0.27$.

In addition, we found that albumin levels could be used as an indicator of mortality with mFI in our study. The preoperative albumin level was lower in the complication group than the non-complication group. Albumin is a sensitive indicator of malnutrition. It is a protein in the liver and consists mostly of plasma protein. It regulates plasma volume, tissue fluid balance, and the transport of many endogenous substances ${ }^{18)}$. The aging process in itself is irrelevant in hypoalbuminemia ${ }^{4)}$. However, the elderly may have chronic malnutrition, commonly known as geriatric anorexia ${ }^{4)}$, requiring careful patient care. Albumin has already been recognized as an indicator of postoperative mortality in several studies ${ }^{1,7,18)}$. Although it is desirable to normalize albumin levels before surgery, further research is needed to find out whether albumin administration may contribute to lower mortality in patients with hypoalbuminemia $^{14)}$.

This study had some limitations. Firstly, it was retrospective; and therefore, the individual disease state of the patient group was not constant. However, our group of patients over 75 years included many patients who were very frail. Secondly, our sample was small size, and therefore, larger multi-center prospective studies are needed to verify our results.

\section{CONCLUSION}

The $\mathrm{mFI}$ is useful in predicting postoperative major complications in patients under 75 years who undergo spine surgery with instrumentation. In addition, low levels of albumin and preoperative infection and trauma were risk factors for postoperative complications. Evaluation of the mFI before surgery may provide very helpful information for counseling patients before surgery.

\section{CONFLICTS OF INTEREST}

No potential conflict of interest relevant to this article was reported.

\section{INFORMED CONSENT}

Informed consent was obtained from all individual participants included in this study.

\section{AUTHOR CONTRIBUTIONS}

\author{
Conceptualization : SJH \\ Data curation : JYK, YSL \\ Formal analysis : YSL, DHK, ISP \\ Funding acquisition : $\mathrm{SJH}$ \\ Methodology : JKK, YSL, KTK \\ Project administration : JKK, SJH \\ Visualization : JKK \\ Writing - original draft : JKK \\ Writing - review \& editing : JKK
}

\section{ORCID}

$\begin{array}{ll}\text { Ji-Yoon Kim } & \text { https://orcid.org/0000-0001-7998-8936 } \\ \text { In Sung Park } & \text { https://orcid.org/0000-0002-8084-8401 } \\ \text { Dong-Ho Kang } & \text { https://orcid.org/0000-0002-1932-5898 } \\ \text { Young-Seok Lee } & \text { https://orcid.org/0000-0002-6881-812X } \\ \text { Kyoung-Tae Kim } & \text { https://orcid.org/0000-0003-4867-6854 } \\ \text { Sung Jin Hong } & \text { https://orcid.org/0000-0001-9353-2644 }\end{array}$

\section{References}

1. Adams P, Ghanem T, Stachler R, Hall F, Velanovich V, Rubinfeld I : Frailty as a predictor of morbidity and mortality in inpatient head and neck surgery. JAMA Otolaryngol Head Neck Surg 139 : 783-789, 2013

2. Afilalo J, Mottillo S, Eisenberg MJ, Alexander KP, Noiseux N, Perrault 
$L P$, et al. : Addition of frailty and disability to cardiac surgery risk scores identifies elderly patients at high risk of mortality or major morbidity. Circ Cardiovasc Qual Outcomes 5 : 222-228, 2012

3. Ali R, Schwalb JM, Nerenz DR, Antoine HJ, Rubinfeld I : Use of the modified frailty index to predict 30-day morbidity and mortality from spine surgery. J Neurosurg Spine 25 : 537-541, 2016

4. Cabrerizo S, Cuadras D, Gomez-Busto F, Artaza-Artabe I, Marín-Ciancas $F$, Malafarina $V$ : Serum albumin and health in older people: review and meta analysis. Maturitas 81 : 17-27, 2015

5. Flexman AM, Charest-Morin R, Stobart L, Street J, Ryerson CJ : Frailty and postoperative outcomes in patients undergoing surgery for degenerative spine disease. Spine J 16 : 1315-1323, 2016

6. Fried LP, Tangen CM, Walston J, Newman AB, Hirsch C, Gottdiener J, et al. : Frailty in older adults: evidence for a phenotype. J Gerontol A Biol Sci Med Sci 56 : M146-M156, 2001

7. Gibbs J, Cull W, Henderson W, Daley J, Hur K, Khuri SF : Preoperative serum albumin level as a predictor of operative mortality and morbidity: results from the National VA Surgical Risk Study. Arch Surg 134 : 3642, 1999

8. Goeteyn J, Evans LA, De Cleyn S, Fauconnier S, Damen C, Hewitt J, et al. : Frailty as a predictor of mortality in the elderly emergency general surgery patient. Acta Chir Belg 117 : 370-375, 2017

9. Hackett NJ, De Oliveira GS, Jain UK, Kim JY : ASA class is a reliable independent predictor of medical complications and mortality following surgery. Int J Surg 18 : 184-190, 2015

10. Iqbal J, Denvir M, Gunn J : Frailty assessment in elderly people. Lancet 381 : 1985-1986, 2013

11. Jain A, Hassanzadeh $H$, Puvanesarajah V, Klineberg EO, Sciubba DM, Kelly MP, et al. : Incidence of perioperative medical complications and mortality among elderly patients undergoing surgery for spinal deformity: analysis of 3519 patients. J Neurosurg Spine 27 : 534-539, 2017

12. Kovacs J, Moraru L, Antal K, Cioc A, Voidazan S, Szabo A : Are frailty scales better than anesthesia or surgical scales to determine risk in car- diac surgery? Korean J Anesthesiol 70 : 157-162, 2017

13. Leven DM, Lee NJ, Kothari P, Steinberger J, Guzman J, Skovrlj B, et al. : Frailty index is a significant predictor of complications and mortality after surgery for adult spinal deformity. Spine (Phila Pa 1976) 41 : E1394E1401, 2016

14. Liumbruno GM, Bennardello F, Lattanzio A, Piccoli P, Rossettias G; Italian Society of Transfusion Medicine and Immunohaematology (SIMTI) : Recommendations for the use of albumin and immunoglobulins. Blood Transfus 7 : 216-234, 2009

15. Makary MA, Segev DL, Pronovost PJ, Syin D, Bandeen-Roche K, Patel P, et al. : Frailty as a predictor of surgical outcomes in older patients. J Am Coll Surg $210:$ 901-908, 2010

16. Mitnitski AB, Graham JE, Mogilner AJ, Rockwood K : Frailty, fitness and late-life mortality in relation to chronological and biological age. BMC Geriatr $2:$ 1, 2002

17. Mitnitski AB, Mogilner AJ, Rockwood K : Accumulation of deficits as a proxy measure of aging. ScientificWorldJournal 1 : 323-336, 2001

18. Montomoli J, Erichsen R, Antonsen S, Nilsson T, Sørensen HT : Impact of preoperative serum albumin on 30-day mortality following surgery for colorectal cancer: a population-based cohort study. BMJ Open Gastroenterol 2 : e000047, 2015

19. Rockwood K, Song X, Mitnitski A : Changes in relative fitness and frailty across the adult lifespan: evidence from the Canadian National Population Health Survey. CMAJ 183 : E487-E494, 2011

20. Torpy JM, Lynm C, Glass RM : Frailty in older adults. JAMA $296: 2280$, 2006

21. Tsiouris A, Hammoud ZT, Velanovich V, Hodari A, Borgi J, Rubinfeld I : A modified frailty index to assess morbidity and mortality after lobectomy.

J Surg Res $183:$ 40-46, 2013

22. Zizza CA, Ellison KJ, Wernette CM : Total water intakes of communityliving middle-old and oldest-old adults. J Gerontol A Biol Sci Med Sci 64 : 481-486, 2009 